\title{
RECORDAR LA DICTADURA CHILENA VISITANDO LUGARES DE MEMORIA
}

\author{
LEMBRAR DA DITADURA CHILENA VISITANDO LOCAIS DE MEMÓRIA \\ REMEMBERING THE CHILEAN DICTATORSHIP BY VISITING PLACES \\ OF MEMORY
}

http://dx.doi.org/10.1590/1807-0310/2018v30179978

Roberto Fernández Droguett ${ }^{1}$, Loreto López González ${ }^{1}$ e Isabel Piper Shafir ${ }^{1}$

${ }^{1}$ Universidad de Chile, Santiago, Chile

\section{RESUMEN}

En el marco de los estudios sobre lugares de memoria vinculados a las violaciones a los derechos humanos cometidas por la dictadura cívico-militar en Chile (1973-1990), este artículo presenta el análisis de visitas a dos lugares de memoria de Santiago de Chile - Villa Grimaldi y Londres 38 - realizadas por personas de distintos grupos etarios. El análisis aborda la interacción de los visitantes con el lugar, considerando los afectos y percepciones que provoca la visita, y la interpelación que estos lugares hacen a las memorias que los visitantes construyen sobre el pasado reciente. Los resultados muestran que, si bien existe acuerdo en la condena a las violaciones a los derechos humanos y la importancia de una cultura de la memoria y los derechos humanos, se produce una distancia entre las generaciones al valorar conflictos del pasado que refieren a distintos momentos históricos.

Palabras clave: memoria colectiva; dictadura; lugar de memoria; violaciones a los derechos humanos; memorias generacionales.

\section{RESUMO}

No marco dos estudos sobre os lugares de memória vinculados às violações dos direitos humanos cometidos pela ditadura cívico-militar no Chile (1973-1990), este artigo apresenta a análise de visitas a dois lugares de memória de Santiago do Chile - Villa Grimaldi y Londres 38 - realizadas por pessoas de diferentes faixas etárias. $\mathrm{O}$ estudo aborda a interação dos visitantes com o lugar, considerando os sentimentos e as percepções que a visita provoca e a interpelação que estes lugares fazem às memórias que os visitantes constroem sobre o passado recente. Os resultados mostram que, embora haja acordo na condenação das violações dos direitos humanos e na importância de uma cultura de memória e dos direitos humanos, um distanciamento entre as gerações aparece ao avaliar conflitos do passado que se referem a diferentes momentos históricos.

Palavras-chave: memória coletiva; a ditadura, lugar de memória; violações dos direitos humanos; memórias de gerações.

\begin{abstract}
In the framework of the studies on places of memory related to human rights violations committed by the Chilean military-civic dictatorship (1973-1990), this article presents the analysis of visits to two places of memory of Santiago de Chile - Villa Grimaldi and London 38 - made by people of different age groups. The analysis addresses the interaction of the visitors with the place, considering the affections and perceptions that the visit caused, and the interpellation that these places cause to the memories that the visitors build on the recent past. The results show that, although there is an agreement on the condemnation of human rights violations and the importance of a culture of memory and human rights, there is a distance among the generations when assessing past conflicts that refer to different historic moments.
\end{abstract}

Keywords: collective memory; dictatorship; place of memory; violations of human rights; generational memories. 


\section{Introducción}

En los últimos veinte años, tanto en Chile como en otros países del Cono sur latinoamericano que vivieron dictaduras o conflictos internos, se ha consolidado un campo de estudio de las memorias colectivas referido al pasado reciente y sus consecuencias en el presente democrático (Crenzel, 2010; Jelin, 2002a; Lira, 2009; Richard, 2010; Ruderer, 2010; Sarlo, 2007; Sosa \& Mazzucchi, 2012; Piper, Fernández \& Iñiguez, 2013; Winn, 2014). El interés principal de las investigaciones del campo ha sido la descripción y análisis de memorias colectivas asociadas a las experiencias de violaciones a los derechos humanos, el impacto de las medidas de la justicia transicional, como Comisiones de verdad, políticas de reparación y procesos judiciales, entre otras, en la elaboración y debate público de versiones del pasado reciente, y la configuración de espacios y acciones de conmemoración llevadas adelante por colectivos de la sociedad civil o el Estado (Jelin, 2002b; Jelin \& Langland, 2002; Hite, 2013; Schindel \& Colombo, 2015). De manera disímil en la región, el campo ha experimentado un desplazamiento hacia nuevos temas, problemas y sujetos, como la elaboración del pasado a través de la producción cultural (música, cine, televisión, literatura y teatro, por ejemplo), la construcción de memorias en la generación de hijos de víctimas y de quienes vivieron las dictaduras siendo niños (Arfuch, 2015; Grunow, 2017; Jara, 2016), o quienes no sufrieron las violaciones a los derechos humanos ni formaron parte de los aparatos represivos (Carassai, 2013; Caviglia, 2006), y la relación de las memorias del terrorismo de Estado con las nuevas generaciones (Fried, 2016).

En Chile, tanto iniciativas estatales como de la sociedad civil han contribuido al procesamiento del pasado dictatorial. Mientras el Estado adoptó algunas recomendaciones de la justicia transicional conducentes a la búsqueda de verdad, justicia y la implementación de medidas de reparación, incluyendo en estas últimas acciones de reparación simbólica a través del apoyo a iniciativas de memorialización a través de la construcción de memoriales y monumentos en homenaje a las víctimas, contribuyendo a la extensión de esta práctica en todo el territorio (FLACSO, 2007; Piper \& Hevia, 2012). Por su parte, la sociedad civil representada por agrupaciones de víctimas, sus familiares y amigos, ha demandado el acceso a recintos que durante la dictadura fueron utilizados como centros de detención y tortura, para recuperarlos y transformarlos en lugares de memoria (Bustamante, 2016; Collins \& Hite, 2013; GómezBarris, 2010; Lazzara, 2007, 2011; López, 2011,
2014). Monumentos, memoriales y ex recintos de detención recuperados se han convertido en objeto de una diversidad de estudios, que abordan los procesos de señalamiento y construcción de símbolos materiales (Aguilera, 2013; Rozas, 2014), las narrativas y actores a los que están vinculados (Fernández, 2015; López, 2011; López, 2014; Piper \& Hevia, 2012), así como los usos que de ellos se hace, destacando el valor que esos espacios tienen para los colectivos de víctimas y otros grupos sociales generalmente vinculados a la defensa de los derechos humanos (Piper, Fernández \& Iñiguez, 2013). Un aspecto menos estudiado es la relación que con esos lugares establecen personas que no son víctimas de violaciones a los derechos humanos o que colaboraron en su desarrollo sin tener un vínculo testimonial con el espacio (Reyes, Cruz, \& Aguirre, 2016). Se trata de los potenciales visitantes a los lugares de memoria, a los que por lo general estos espacios pretenden a atraer o interpelar, sobre todo a las generaciones más jóvenes.

La relación entre estos espacios con sujetos que no corresponden a los emprendedores de memoria ni a los gestores del lugar, resulta fundamental para comprender el poder que éstos tienen en el procesamiento del pasado desde un punto de vista social más amplio, más allá de las funciones de reparación simbólica hacia las víctimas que está contenida en todos ellos. Abordar esta relación permitiría conocer las potencialidades que estos lugares tienen para la construcción de memorias en otros actores sociales, pertenecientes a distintas generaciones, y que no fueron víctimas directas de violaciones a los derechos humanos. Indagaciones en este ámbito logran relacionar la atención hacia los lugares de memoria con el más reciente interés por otro tipo de sujetos y posibles memorias que se ha venido instalando en este campo de estudios en la región. En esta línea, entre los años 2011 y 2013 desarrollamos una investigación sobre la construcción de relatos generacionales sobre el pasado reciente de Chile, con visitantes a lugares de memoria, a través de la cual buscábamos conocer cómo sujetos no-víctimas interactúan con los lugares de memoria, y qué narrativas sobre el pasado reciente construyen al relacionarse con estos lugares. Las y los participantes del estudio fueron seleccionados tomando en cuenta que no hubiesen sido víctimas directas de atropellos a los derechos humanos durante la dictadura, ni fueran familiares directos de víctimas de violaciones a los derechos humanos, cuyos discursos, según algunos autores, se han convertido en memorias dominantes o hegemónicas sobre el pasado reciente (Da Silva, 2010; Stern \& Winn, 2014). Asimismo, considerando que una parte importante de la población chilena era muy joven o no había nacido en el momento del golpe de 
Estado y durante la dictadura (1973-1990), se convocó a personas de diferentes grupos etarios, de modo de abarcar la mayor variedad posible de narrativas sobre el pasado que surgiesen a partir de la experiencia de la visita a los lugares de memoria.

La producción de datos se desarrolló en dos momentos, siguiendo las metodologías del acompañamiento dialógico (Espinoza, Piper \& Fernández, 2014) y del grupo triangular (Conde 2008; Ruiz, 2012). Se realizaron un total de 48 acompañamientos y 16 grupos triangulares en los cuatro lugares de memoria (12 acompañamientos y 4 grupos, por cada lugar). En cada lugar se invitaba en una misma ocasión a tres participantes, las que recorrían el lugar de manera libre acompañada en compañía de un miembro del equipo de investigación con quien iban comentando sus puntos de vista e impresiones sobre esta experiencia. En función de la propuesta metodológica del acompañamiento dialógico, la labor de acompañamiento del/la investigador/a era registrar audiovisualmente el recorrido y los comentarios de cada participante, haciendo preguntas de modo de poder generar un dialogo que permitiera que el/la participante compartiera sus impresiones. Una vez terminado el recorrido, se reunía a la/os participantes una conversación grupal para compartir sus experiencias y elaborar conjuntamente relatos de memoria. Esta conversación grupal se desarrollaba siguiendo la metodología del grupo triangular (Conde 2008; Ruiz, 2012), consistente en una conversación abierta en la que un miembro del equipo de investigación realiza algunas preguntas, con un estilo no directivo, sobre la experiencia del recorrido, de modo de producir un discurso grupal compartido de carácter vivencial que considerara no solamente los aspectos comunes sino también los matices y diferencias de la experiencia. El análisis se orientó a los componentes del discurso relativos la interacción de los sujetos con el espacio durante el recorrido y a las memorias producidas en torno a esta experiencia (Espinoza et al., 2014). En el presente artículo nuestro análisis se centra específicamente en los resultados obtenidos en los dos grupos etarios de mayor edad que participaron en la investigación (entre 30 y 60 años, y 61 y más años), entre los cuales se manifestó un mayor dialogo, y en algunos casos tensión, con las memorias ofrecidas por los lugares, específicamente "Parque por la Paz Villa Grimaldi" y "Londres 38, espacio de memorias", y las elaboraciones de memoria que a través de ellas se producen. Villa Grimaldi y Londres 38 corresponden a un mismo tipo de lugar de memoria, a saber, ex centros de detención recuperados y abiertos al acceso público durante la post-dictadura en la ciudad de Santiago, capital de Chile. En estos lugares conviven vestigios de la época previa a su uso como recintos de detención, y de cuando cumplieron funciones represivas, junto a otras intervenciones memoriales, informativas y funcionales introducidas luego de la recuperación y apertura. En este sentido comparten la condición de ser testigos materiales de los acontecimientos a los que aluden las memorias vinculadas a ellos.

\section{Los lugares de memoria}

Para aproximarse a la potencialidad que los memoriales, monumentos, ex recintos de detención recuperados e incluso marcas en el territorio, tienen para invocar e interpelar determinadas visiones del pasado, utilizamos el concepto de "lugar de memoria" acuñado por Pierre Nora, al que se refiere como lugares "en los tres sentidos de la palabra: material, simbólico y funcional, pero simultáneamente en grados diversos. Incluso un lugar de apariencia puramente material, como un depósito de archivos, solo es lugar de memoria si la imaginación le confiere un aura simbólica" (Nora, 2009, p. 32). Por su parte, Piper \& Hevia (2012) los definen como "aquellos espacios significativos que son usados y apropiados por medio de acciones de recuerdo que enuncian, articulan e interpretan sentidos del pasado" (p. 15). En este sentido, un lugar de memoria es el resultado de una acción y una intención movilizada por un colectivo social, donde su valor es construido según las circunstancias del presente, y sus marcas son significativas para una determinada memoria colectiva. En sí, un lugar no comporta una relevancia a priori, sino que debe ser activado gracias a acciones intencionadas de incorporación de ellos a una determinada narrativa sobre el pasado. En el caso específico de los ex centros de detención recuperados, se trata de mediaciones entre lo que una materialidad primera ofrece, el vestigio por ejemplo, y las significaciones atribuidas a ella por determinadas memorias colectivas, a través de procesos de calificación o marcación que atribuyen valor y sentido; descalificación, es decir acciones que borran esas atribuciones; y recalificación, a través de acciones que articulan nuevos valores y sentidos (Fleury \& Walter, 2011; AUTOR 3 et al., 2013). Dicho de otra forma, si las huellas son materiales, los hechos o acontecimientos asociados a ellas son necesariamente una construcción basada en la posibilidad de poder narrar qué ocurrió en el lugar, cuándo, cómo, con quiénes, etc. En la medida que los significados sobre el pasado no están establecidos de una vez y para siempre, sino que son dinámicos y cambiantes, los ex recintos de detención en su condición de lugar de memoria operan como espacios donde esos significados se inscriben, pero también se problematizan, se tensionan y eventualmente se transforman. De esta manera el 
mensaje asociado a un lugar puede ser interpretado de formas diferentes e incluso contradictorias (Piper \& Hevia, 2013). Lo que, siguiendo a Achugar (2003), puede entenderse como la tensión entre las dimensiones enunciativa e interpretativa de un lugar. La tensión señalada, se traduce en que el sentido que distintas personas y grupos le atribuyen al lugar se elabora y re-elabora en cada experiencia con el espacio, en la cual los significados sobre el pasado se enlazan con los significados sobre el lugar. Esto es así pues la interacción con un lugar de memoria supone una forma de contacto y diálogo entre memorias en el escenario provisto por los lugares -sus estéticas, materialidades e informaciones disponibles-. Yendo más allá, las formas en que se produce el diálogo entre memorias en un lugar, remite también a los usos que puede hacerse de la memoria, ya sea para comunicar literal y singularmente los hechos que se recuerdan en el lugar, o para relacionar esos acontecimientos con otros momentos, otros sujetos y experiencias, de manera ejemplar (Todorov, 2000), lo que llevaría a un cuestionamiento personal y a un aprendizaje sobre el pasado.

A la vez, en la relación que distintos sujetos establecen con los lugares de memoria interviene la posición generacional (Mannheim, 1993) en la cual se sitúan respecto los acontecimientos históricos que aportan identidad al sitio y los marcos sociales que orientan la construcción de la memoria de éste (Halbwachs, 2004). Por una parte, se trata de un posicionamiento fundado en la conciencia de haber vivido juntos un mismo momento histórico, más allá de la confluencia que pueda haber en los juicios que se sobre él se elaboran o en las formas cómo se recuerda, pues como señala Cuesta (2007) "la unidad de una generación no implica la unidad de memorias" (p. 7), ya que las vivencias y luego las representaciones del período pueden variar dentro de la misma generación. Por otra, la disposición hacia la memoria y mensaje propuesto por el lugar en el presente, puede conducir también a un posicionamiento generacional, no sólo por referencia a los hechos que se recuerdan, sino también a la forma en cómo se ejecuta ese recuerdo a través de las condiciones materiales y simbólicas que presenta el lugar. Lo anterior es posible porque los lugares desarrollan un trabajo con la espacialidad y la materialidad con el fin de situar y comunicar sus memorias. De esta manera, a través de distintos recursos y elementos, sean conmemorativos, didácticos, infográficos, e incluso el vacío o la escasez de información, se propone una determinada visión del pasado. Es por ello que en la experiencia de visita a un lugar de memoria es posible abordar tanto las dimensiones sensoriales y emocionales de la interacción, como las elaboraciones de memoria y conocimientos producidos por los visitantes.

\section{Escenarios para el recuerdo: Villa Grimaldi y Londres 38}

Los lugares de memoria conocidos como Villa Grimaldi y Londres 38, formaron parte de la red de recintos de detención implementados por la dictadura en la ciudad de Santiago, y fueron recuperados y abiertos a la ciudadanía en 1994 y 2007 respectivamente. Si bien tras su recuperación Villa Grimaldi y Londres 38 se inscriben en una misma categoría de lugar de memoria, es preciso señalar que su configuración espacial y estética difiere en cuanto al tipo, número y magnitud de las intervenciones que en ellos han efectuado los emprendedores de memoria asociados a los procesos de recuperación y gestión de esos espacios. Villa Grimaldi se presenta como un parque memorial emplazado en los 10 mil metros cuadrados donde estuvo ubicado un centro clandestino de detención y tortura que, tras el cese de sus actividades represivas, se habría comenzado a degradar materialmente por abandono y finalmente por la acción deliberada de destrucción ejecutada por el último director de los antiguos servicios de inteligencia de la dictadura quien fraudulentamente vendió la propiedad a una empresa constructora de su familia para edificar un conjunto habitacional. Como en otros ex recintos de detención, la destrucción de Villa Grimaldi ocurrió mientras un movimiento de la sociedad civil se había organizado para conseguir su recuperación, durante los primeros años de la postdictadura, de esta forma una vez recuperado el predio fue encontrado en una condición de arrasamiento donde las antiguas edificaciones asociadas al centro clandestino subsistían como ruinas, lo que derivó en la decisión de construir un artefacto memorial en la forma de parque, caracterizado por una arquitectura simbólica que estructuró el espacio a través de la combinación de elementos escultóricos y paisajismo, distanciándose de una opción reconstructiva o restauradora de la materialidad preexistente. Esta decisión fundacional ha hecho posible la constante adherencia de diversos elementos al proyecto original del Parque como sitio de memoria, incorporando más de treinta intervenciones de diverso carácter, tales como elementos conmemorativos, reconstrucciones, señaléticas, puesta en valor de vestigios, equipamiento y servicios para la atención de visitantes, entre otros elementos (López, 2014). Por su parte, Londres 38 subsiste como una antigua casona de la oligarquía local en pleno centro de la ciudad que, tras su uso como sede de un partido político perseguido por la dictadura, fue ocupada como recinto de detención y traspasada luego 
a una organización cercana al Ejército. Al momento de su recuperación durante los años 2000, el inmueble se encontraba deteriorado pero aún en pie, ante lo cual el colectivo que comenzó a gestionar el espacio optó por mantener el recinto relativamente vacío, con mínimas intervenciones informativas y escasa alteración de su condición ruinosa (Aguilera, 2013).

Es importante hacer notar que en ambos casos, ya sea por adicionamiento de elementos diversos, como por la ausencia de intervenciones, el visitante se enfrenta a una insuficiente información histórica, sencilla y precisa, sobre la relación de estos centros de detención con la red represiva de la dictadura, y sobre las dinámicas de operación del recinto. Aunque nuestro análisis no se centra en la descripción de las materialidades y configuraciones espaciales de cada lugar, es importante considerar que la interacción de los visitantes con ellos se desarrolla a partir de la percepción inmediata del espacio y sus componentes. En este sentido la mediación memorial que se ejerce en los lugares, descansa primeramente en la manera cómo éstos se presentan o aparecen ante el visitante.

\section{Interactuando con los lugares de memoria}

Para abordar el análisis de la interacción con los lugares de memoria escogidos, se desarrollan dos aspectos de los resultados obtenidos en la investigación, por una parte, aquellos relacionados con el impacto afectivo que produce en los sujetos recorrer los lugares; y por otra, cómo a partir de ese impacto configuran una posición de compromiso con la memoria, los derechos humanos y la democracia. Para esto se seleccionaron y analizaron citas de los grupos triangulares en cuestión, de modo de dar cuenta de los principales elementos comunes y diferentes de la experiencia de los participantes en cada lugar $\mathrm{y}$ de cómo a partir de dicha experiencia se producen discursos de memoria que articulan el pasado con el presente.

\section{El impacto afectivo y sus sentidos}

Al relatar la experiencia de interactuar con los lugares de memoria, lo primero que aparece en lo sujetos participantes es un importante impacto físico y emocional, que se manifiesta en referencias a sensaciones como dolor de estómago, escalofríos, incomodidad, remecimiento:

- Ahi es donde a uno se le paran los pelos, ahi fue donde te dije, ahi quedé con dolor de guata... [estómago]"
- A mí, a mí me produjo como te digo, la piscina me produjo escalofríos

(Villa Grimaldi, Grupo mayor de 60 años)

- es incómoda, te fijas? no es una sensación grata, para nada

- lo que me remece, es la placa que te diga que aquí se torturó con vehículos

(Villa Grimaldi, Grupo entre 30 y 60 años)

En el caso de Londres 38, el impacto se expresa en deseos de llorar, relacionada a sentimientos de angustia, rabia e impotencia:

- Mmm... si, me cuesta hablar

- Yo a ratos tenía ganas de llorar, pero a gritos. Si hubiera podido...

- Si, yo también.

- Te juro, llorar pero así a moco tendido, en dos oportunidades del recorrido sentí angustia y en otros momentos sentí mucha rabia, rabia de que... se hubiese hecho todo eso, impotencia no sé.

(Londres 38, Grupo entre 30 y 60 años)

En Villa Grimaldi, las marcas que refieren directa y literalmente al recuerdo de la represión ejercida en el lugar, como por ejemplo mosaicos a nivel de suelo que señalan el uso de represivo -confinamiento y tortura- de distintos espacios al interior del ex recinto de detención, producen una tensión e incomodidad, que sin embargo es matizada por las características del lugar: abundante vegetación, elementos ornamentales e intervenciones conmemorativas que le dan forma de Parque. El aroma de las flores, el sonido del agua y el canto de los pájaros, son estímulos que, en su contrapunto con las señas a la experiencia represiva, son percibidos como formas de pacificación y purificación de los horrores ocurridos en el lugar, en una especie de acción exorcizante.

esta es la transformación que hicieron los familiares, como para apaciguar supongo yo la pena, el dolor y la rabia que han sentido, y en ese sentido yo creo que uno trata como de hacer agradable, no, no es agradable, de hacerlo más llevadero. (Villa Grimaldi, Grupo entre 30 y 60 años)

De este modo, las intervenciones realizadas en Villa Grimaldi operan como atenuantes del duro impacto afectivo que tiene visitar el lugar. En el caso de Londres 38, las sensaciones que relevan los sujetos participantes son similares a las que emergen en Villa Grimaldi. Sin embargo, las características propias del espacio - un edificio mayormente vacío, no restaurado, 
donde priman los colores grises y una estructura arquitectónica deteriorada por el tiempo- son los elementos que intensifican el impacto.

me produjo una impresión como de malas vibras en general, a pesar que tiene colores bastante suaves, que me pasan, pero demasiados recovecos, demasiados laberintos, y esas escaleras asi hacia abajo también me provocaron una impresión bastante. (Londres 38, Grupo mayor de 60 años)

A diferencia de lo que sucede en Villa Grimaldi, en Londres 38 el relato de la experiencia de los sujetos participantes no hace referencias positivas al lugar. La evocación de sensaciones negativas va acompañada de percepciones de lo frío, feo y desagradable, lo que induce a los sujetos imaginar los hechos represivos que ahí sucedieron de manera más rápida y directa. Cabe destacar que referir imaginariamente las situaciones de violencia vivida por las víctimas es común a la mayor parte de los sujetos participantes, lo cual da cuenta del imaginario social sobre los atropellos a los derechos humanos y cómo éste opera en un espacio donde no existe ninguna indicación detallada de esos acontecimientos, como el caso de Londres 38.

en una habitación de allá, que da a una ventana después para abajo una escalera, no sé, esa estructura de la casa como que me gatillaba imaginarme como hacian subir a los presos, bajar. Me imaginaba vendada (simula una venda con sus manos sobre los ojos), me imaginaba como que los trataban de desorientar, ¿me entiendes tú? (Londres 38, Grupo entre 30 y 60 años)

Si bien en ambas generaciones las sensaciones negativas son relativamente parecidas, las reflexiones que desarrollan a partir de ellas apuntan en diferentes direcciones. Para el grupo más joven (30 a 60 años), el impacto emocional del lugar les permite conectarse con las violaciones a los derechos humanos allí perpetradas, transformando la visita en una experiencia imborrable que les hace ponerse en el lugar de las víctimas, sensibilizarse y al mismo tiempo querer transmitir a la sociedad lo que sucedió, y así promover que esos hechos no se repitan.

ahora estaba pensando que es un lugar donde tengo que traer, por ejemplo, a mi mamá, a mi suegra, e incluso a gente que sigue desconociendo la magnitud de lo que pasó en lugares como este, ni siquiera lo que pasó a nivel global, que siguen no dando crédito a que esas cosas pudieron haber pasado. (Villa Grimaldi, Grupo entre 30 y 60 años)

En el caso del grupo de mayor edad (sobre 60 años), aunque hay referencias a la importancia de conocer y transmitir los hechos, se expresa una visión más crítica del lugar y de lo que promueve. Uno de los participantes plantea que es necesario recordar, pero haciéndolo de forma positiva, alejándose de una "memoria de la odiosidad".

Yo encuentro que ... a ver, para las personas que si estuvieron aqui y que deben haber venido debe ser terriblemente fuerte, recordar y vivir de nuevo lo que vivieron y todo eso, y para la familia de los que desaparecieron y todo. Pero no sé, lo encuentro como que es seguir manteniendo una memoria de la odiosidad. (Villa Grimaldi, Grupo mayor de 60 años)

Como se verá con más detalle a continuación, las sensaciones que producen la interacción con los espacios sientan las bases para la elaboración de significados tanto sobre el lugar como sobre el pasado, donde el mandato de recuerdo de las víctimas y de respeto de los derechos humanos se cruza con la necesidad de alejarse de los conflictos del pasado. Esto aparece con mayor fuerza en el grupo de personas mayores a 60 años, quienes sustentan su posición en sus experiencias personales durante el periodo de la Unidad Popular y la dictadura.

\section{Posicionamientos sobre el pasado y el presente}

Mientras los grupos considerados en este análisis manifiestan coincidencias en la experiencia sensitiva y emotiva con Villa Grimaldi, al enfrentarse a la memoria que promueve el lugar emergen posiciones diversas. Por una parte, el grupo entre 30 y 60 años tiende a asumir que el lugar espera algo de ello/as, en este caso asumir una posición a partir del llamado de atención que implican este tipo de lugares. Se trata de una interpelación moral basada en la aceptación incondicional de la ética de los derechos humanos y una adscripción a los valores de la democracia y el Nunca Más como consigna que asumen como propia, consigna proveniente de la lucha por los derechos humanos durante la dictadura en Chile y que posteriormente en democracia se convierte en un compromiso social y político relativo a que no vuelvan a repetir las violaciones a los derechos humanos.

te refresca la memoria, te hace tomar conciencia, te hace tomar una posición, pero una posición real

no puede volver a ocurrir lo que ocurrió, o sea, sin justificar, sin hacer apología de por qué se produjeron los hechos que tuvieron que ver con la creación de estos lugares, no puede ocurrir nunca más, o sea este es un llamado de atención. (Villa Grimaldi, Grupo entre 30 y 60 años)

Para los mayores de 60, el pasado al que remite Villa Grimaldi no es necesariamente aquel en el cual 
ocurrieron los hechos y que motivaron la construcción del lugar de memoria, sino el período inmediatamente anterior al Golpe de Estado - el de la Unidad Popularque persiste como un tiempo de crisis, donde dicen "cualquier cosa podía haber pasado". La experiencia directa de este grupo en su calidad de testigo, colma la conversación de referencias a situaciones acontecidas, y actualiza el recuerdo de una sociedad polarizada donde todos se veían conminados a elegir una posición dentro de la dicotomía entre derecha e izquierda.

Entonces cada persona eligió su sitio, me entiendes tú, y cada cual persona eligió lo que ella creía que era su ideal. Ahora, que es lo que critico de estas dos porciones y te lo vuelvo a explicar. Que tanto de derecha como de izquierda se polarizó esto de forma espantosa. Ahi eras de derecha o de izquierda.? (Villa Grimaldi, Grupo mayor de 60 años)

Esta suerte de memoria de la polarización se reconoce como un marco que se ha construido para abordar el pasado, y que también se actualiza frente a las situaciones de protesta y movilización social del presente mencionadas por los propios participantes, en las que se advierte una vuelta a las posiciones extremas. Asimismo, la idea de que en el presente en algún sentido se repite la polarización del pasado, instala el miedo y cierta expectativa de que las consecuencias de la polarización, como la violencia política y los atropellos a los derechos humanos, puedan volver a repetirse.

El que no vivió el tema, aun con este y otros lugares fijate, es imposible que capte realmente lo que entonces sucedió. Lo que estás diciendo tú, obviamente lo vivi yo también, y eso, no solamente no es fácil de comunicar a uno que no vivió, hijos, por ejemplo, no sólo no es fácil, sino que está influido además por la otra condición. La exaltación del otro sector. Es decir, blanco y negro. Allende y Pinochet ... Y ahora se está volviendo a lo que había antes de Pinochet, lo que estamos comentando, y nuevamente, blanco y negro. ... Pero esto ya pasó, así fue el inicio. $Y$ ese es el terror mio. (Villa Grimaldi, Grupo mayor de 60 años)

En el caso de Londres 38, las referencias de la generación mayor de 60 años a un pasado conflictivo han sido definidas como la memoria de la odiosidad, la que se entiende como una forma de recordar que debe ser abandonada. Alejarse de la odiosidad aparece entonces como un imperativo dirigido a las nuevas generaciones, las que deberían encontrarse con un lugar que proponga una memoria más positiva.

que sea un espacio para la juventud, por último, y tenemos el memorial de la gente que lo pasó mal aquí y la que desapareció, y qué sé yo!, pero no como tema de vengamos a recordar esto que hicieron ... no se puede seguir en forma indefinida el tema, una vez que desaparezca nuestra generación, hay que tener un recuerdo 'general' para evitar que se repita esto, en el fondo. (Londres 38, Grupo mayor de 60 años)

Para ellos una aproximación más positiva al pasado se lograría con la realización de actividades artísticas y de otro tipo que le den "vida" al lugar.

exposiciones, y como te digo, hasta música, algo de vida, vida, no tratar de tener esto, asi como 'mausoleo'. ... Tener un monolito una cosa así, tener una placa de recuerdo. Tener un recordatorio de las plaquitas de la gente de lo que... ya está bien, $y$ exposiciones si quieren, de fotos o de otras cosas del momento, una sala para eso, y el resto arreglarlo, arreglar todo esto que está horrendo y darle vida No quedarse en el pasado en el fondo. (Londres 38, Grupo mayor de 60 años)

Aunque el grupo más joven comparte la idea de que el lugar promueva una aproximación más positiva al pasado, se asume que ello no puede estar basado en el alejamiento de los conflictos vividos sino más bien en la lógica de promover el compromiso y la esperanza, como se aprecia en el siguiente diálogo:

- pero por muy desolador que sea este lugar, siempre tienen que dejar ustedes el momento de enseñar lo que sea, dejar un espacio a la esperanza también

- eso también es importante, cosa que la persona que entre no salga 'mal'.

- Siempre hay que hacerlo de tal manera de que la persona salga una actitud de compromiso

- Esperanzador.

(Londres 38, Grupo entre 30 y 60 años)

En los mayores se trata de una lectura ejemplar de carácter catastrofista, que parece dejar a los sujetos sin capacidad de acción en el presente, en tanto lo mismo podría pasar otra vez. Es una memoria que no ha logrado conectar, como si ocurre con la generación más joven (30 a 60 años), con un discurso ético que trasciende las circunstancias históricas específicas, y que podría resultar más efectivo para protegerse contra posibles catástrofes, haciendo un uso ejemplar de la memoria al aprender del pasado. En este sentido, la verdad factual que exhibe el lugar de memoria, desencadena procesos distintos en cada grupo etario. Mientras los más jóvenes experimentan una sensibilización moral, los mayores vuelven al contrapunto con sus experiencias directas, en este caso la de no saber o no conocer la magnitud de la represión ejercida por la dictadura. Esta realidad es advertida por los más jóvenes, quienes se refieren a la generación mayor, no sólo como quienes no conocen lo ocurrido 
en estos lugares sino también como quienes detentan posiciones más inflexibles respecto del pasado, basadas principalmente en el marco de la polarización, al que se refieren como una cultura o paradigma del enemigo propia de los más viejos, y que hoy día sería menos tolerable entre sus pares.

Siento que es como no haber aprendido nada, eso me desilusiona, me decepciona encontrarlo en gente de la edad de uno, o sea incluso hasta lo podría entender en otras personas, o en personas que a lo mejor vivieron las cosas de manera distinta o en gente mayor incluso, pero en gente de la edad nuestra, de nuestra generación, me decepciona profundamente y siento que todavía hay mucho de eso. (Villa Grimaldi, Grupo entre 30 y 60 años)

La asimilación del lugar con una memoria del Nunca Más sostenida en la ética de los derechos humanos y la valoración de la democracia, limita la distancia crítica de los sujetos más jóvenes en relación con lo que estos lugares ofrecen al visitante. En este sentido son más receptivos a la ética y estética propuesta por los sitios, y se someten a ella a través de lecturas que conectan los sucesos represivos con el aprendizaje social de un nuevo marco de convivencia. Por el contrario, la interpelación que los lugares hacen a las propias biografías de los mayores, provoca una conexión con el contexto histórico que vivieron en calidad de testigos. Y si bien, en ambos lugares aceptan la condición de documento histórico de los espacios, es decir que narren lo en ellos ocurrido, plantean la necesidad de proveer un contrapunto de actividades $\mathrm{y}$ ofertas que equilibren el recuerdo de ese pasado negativo.

\section{Discusión: la relación con el pasado para tener lugar en el presente}

Como se señaló en un comienzo, todo lugar de memoria presenta una dimensión enunciativa en torno a la cual se busca comunicar un determinado mensaje. En Chile esta dimensión articula el recuerdo de las víctimas y su reparación simbólica con la promoción de una cultura de la memoria y los derechos humanos (Stern \& Winn, 2014). En el análisis presentado, se observa que en la interacción de personas que no fueron víctimas de violaciones a los derechos humanos con los lugares de memoria considerados en el estudio, ambos propósitos se articulan de manera problemática. En la medida que la aproximación al horror de la experiencia de las víctimas interpela a los sujetos, sobre todo a partir de las dimensiones emocionales y afectivas, ésta deriva en un rechazo genérico al atropello a los derechos humanos. Ahora bien, en el grupo de visitantes de mayor edad, la referencia al periodo histórico en que ocurrieron los atropellos, la dictadura cívico-militar, va junto a su antecesor -el período de la Unidad Popular-, donde este último hasta cierto punto es percibido como un precedente causal del golpe de Estado y sus consecuencias. Y esa relación de causalidad pareciera debilitar el arraigo del mensaje ético del Nunca más que proponen los lugares.

La inclusión del período de la Unidad Popular como parte del recuerdo del pasado reciente, cuestiona también el marco temporal que ha orientado el desarrollo de Villa Grimaldi y Londres 38 como lugares de memoria, el que se basa principalmente en el recuerdo del terrorismo de Estado desplegado entre los años 1973 y 1990. En el caso de los participantes entre 30 y 60 años, estos se muestran más receptivos al marco propuesto por los lugares, marginando referencias al gobierno de Salvador Allende, del cual no fueron testigos oculares, aceptando entonces que los aprendizajes del pasado y la memoria del Nunca Más basada en la valoración de los derechos humanos, como mensaje ejemplar, derivan de los horrores del período dictatorial. Si bien la generación mayor no desautoriza la narrativa de la experiencia de la represión manifiesta en cada lugar, consideran que la ejemplaridad de la memoria residiría en evitar las confrontaciones y posiciones extremas, lo que confirma interpretaciones ofrecidas por análisis de otros autores, donde la referencia al pasado es temida pues amenaza con el regreso del conflicto incontrolable producto de la polarización (Lechner, 2002).

Podría decirse que la fuente escogida para el aprendizaje sobre el pasado puede llevar a una "rebelión generacional" (Sánchez De La Yncera, 1993), por la cual los más jóvenes buscan superar las formas antagónicas de relacionamiento que atribuyen a la generación anterior, y que resulta improductiva para las condiciones del presente. En este sentido, se trata de un grupo que asume su rol en el procesamiento del pasado en el Chile actual, como protagonistas de ese proceso o al menos identificándose con un lugar en él, gracias al compromiso ético que han estado dispuestos a asumir. De esta manera si la visita a lugares de memoria reedita "batallas de memoria" (Jelin, 2002; Winn, 2014), es decir confrontaciones relativas a cómo concebir el pasado y rememorarlo, situación que se hace evidente en las conversaciones sostenidas por las personas mayores en relación con las memorias propuestas por los lugares, también promueve tensiones entre las generaciones (Sánchez De La Yncera, 1993). Como hemos visto, la visita ex recintos de detención transformados en lugares de memoria comporta potencialidades para interpelar la 
construcción de memorias sobre el pasado reciente y acciones en el presente, y la relación que los sujetos establecen con las narrativas propuestas por esos lugares contribuye a su posicionamiento generacional. Sin embargo, a la inversa cabe preguntarse si los lugares de memoria, sus emprendedores y actuales gestores, toman en consideración las formas cómo visitantes que no sufrieron violaciones a los derechos humanos, interactúan con el lugar y las elaboraciones de memoria que se activan a partir de esa interacción, ya sea para comprender el alcance de sus acciones en el espacio público o para dialogar con experiencias y reflexiones que hoy quedan excluidas de los marcos propuestos para recordar el pasado. A partir de esta experiencia de estudio, nos ha resultado evidente que mientras las impresiones afectivas y emocionales, pueden resultar comunes en visitantes de distintas generaciones, el diálogo en torno al pasado reciente no necesariamente conduce a una reflexión sobre las condiciones que hicieron posible el horror al que refieren los lugares, ni siempre a un compromiso con el Nunca más que promueven los lugares.

\section{Referencias}

Achugar, H. (2003). El lugar de la memoria, a propósito de monumentos (motivos y paréntesis). In E. Jelin \& V. Langland (Comps.), Monumentos, memoriales y marcas territoriales (pp. 191-216). Buenos Aires: Editorial Siglo XXI.

Aguilera, C. (2013). Londres 38 y Patio 29: vacíos llenos de recuerdos. La configuración de espacios de memoria a 40 años del golpe militar en Chile. Revista de Geografía Espacios, 3(8), 98-116.

Arfuch, L. (2015). Memoria, testimonio, autoficción. Narrativas de infancia en dictadura. Kamchatka. Revista de análisis cultural, 6, 817-834. https://doi.org/10.7203/KAM.6.7822

Bustamante, J. (2016). Procesos de activación y patrimonialización de sitios de memoria en Chile. 1990 al presente. Aletheia, 7(13), 1-16.

Carassai, S. (2013). Los años setenta de la gente común. La naturalización de la violencia. Buenos Aires: Siglo XXI.

Caviglia, M. (2006). Dictadura, vida cotidiana y clases medias. Una sociedad facturada. Buenos Aires: Editorial Prometeo.

Collins, K. \& Hite, K. (2013). Fragmentos de memoriales, silencios monumentales y despertares en el Chile del siglo XXI. In C. Collins, K. Hite, \& A. Joignant (Eds.), Las políticas de la memoria en Chile: desde Pinochet a Bachelet (pp.161-191). Santiago: Universidad Diego Portales.

Conde, F. (2008). Los grupos triangulares como espacios transicionales para la producción discursiva: un estudio sobre la vivienda en Huelva. In Á. Gordo \& A. Serrano (Coords.), Estrategias y prácticas cualitativas de investigación social (pp. 155-188). Madrid: Pearson Educación.

Crenzel, E. (2010). Políticas de la memoria. La historia del informe nunca más. Papeles del CEIC, 2(61), 1-31.

Cuesta, J. (2007). "Las capas de la memoria”. Contemporaneidad, sucesión y transmisión generaciones en España (19312006). Hispania Nova: Revista de historia contemporánea,
7, 1-33. Recuperado de http://hispanianova.rediris.es/7/ dossier/07d009.pdf

Da Silva, L. (2010). Exponer lo invisible. Una etnografía sobre la transformación de Centros Clandestinos de Detención en Sitios de Memoria en Córdoba-Argentina. In Recordar para pensar. memoria para la democracia. La elaboración del pasado reciente en el Cono Sur de América Latina (pp. 4456). Santiago: Böll Cono Sur.

Espinoza, A., Piper, I., \& Fernández, R. (2014). The study of memory sites through a dialogical accompaniment interactive group method: A research note. Qualitative Research, 14(6), 712-728. Recuperado en https://doi. org/10.1177/1468794113483301

FLACSO. (Ed.). (2007). Memoriales de derechos humanos en Chile: homenajes a las víctimas de violaciones a los derechos humanos entre 1973 y 1990. Santiago de Chile: Autor (Chile).

Fernández, R. (2015). Lugares de memoria de la dictadura en Chile: Memorialización incompleta en el barrio cívico de Santiago. Bitácora Urbano Territorial, 1(25), 131-136.

Fleury, B. \& Walter, J. (2011). De los lugares de sufrimiento a su memoria. In Memorias de la piedra. Ensayos en torno a lugares de detención y masacre (pp. 21-43). Buenos Aires: Editorial Ejercitar la memoria.

Fried, G. (2016). Trauma social, memoria colectiva y paradojas de las políticas de Olvido en el Uruguay tras el terror de Estado (1973-1985): memoria generacional de la postdictadura (1985-2015), ILCEA , 26. Recuperado en http:// ilcea.revues.org/3938

Gómez-Barris, M. (2010). Witness Citizenship: The Place of Villa Grimaldi in Chilean Memory, Sociological Forum, 25(1), 27-46.

Grunow, H. (2017). Hablan los hijos. Tres obras para enriquecer los debates sobre la post-memoria desde el Cono Sur. Critical Reviews on Latin American Research, 6(2), 31-34.

Halbwachs, M. (2004). Los marcos sociales de la memoria. España: Anthropos.

Hite, K. (2013). Política y arte de la conmemoración. Memoriales en América Latina y España. Santiago: Mandrágora.

Jara, D. (2016). Children and the Afterlife of State Violence. Palgrave, US: Palgrave Macmillan.

Jelin, E. (2002a). Los trabajos de la memoria. Madrid: Siglo XXI (España); Social Science Research Council.

Jelin, E. (Ed.). (2002b). Las conmemoraciones: las disputas en las fechas "in-felices". Madrid: Siglo XXI (España); Social Science Research Council.

Jelin, E. \& Langland, S. (Eds.). (2003). Monumentos, memoriales y marcas territoriales. Madrid: Siglo XXI (España); Social Science Research Council.

Lazzara, M. (2007). Prismas de la memoria: narración y trauma en la transición chilena. Santiago: Cuarto Propio.

Lazzara, M. (2011). Dos propuestas de conmemoración pública: Londres 38 y el Museo de la Memoria y los Derechos Humanos (Santiago de Chile), A Contracorriente, 8(3), 55-90.

Lechner, N. (2002). Las sombras del mañana: La dimensión subjetiva de la política. Santiago: Ed. Lom.

Lira, E. (2009). Trauma, duelo, reparación y memoria. Revista de Estudios Sociales, 36, 14-28.

López, L. (2011). Derechos Humanos, patrimonio y memoria. Museos de la memoria y sitios de conciencia. In E. Ximena, 
G. Ramírez, \& M. Scantlebury (Eds.), Derechos Humanos, pedagogía de la memoria y políticas culturales (pp. 127138). Santiago: Editorial Lom.

López, L. (2014). Lugares de memoria de la represión. Contrapunto entre dos ex centros de detención recuperados en Chile y Argentina: Villa Grimaldi y el Olimpo. Tesis para optar al grado de Magister en Estudios Latinoamericanos, Facultad de Filosofía y Humanidades, Universidad de Chile.

Mannheim, K. (1993). El problema de las generaciones. Reis Revista Española de Investigaciones Sociológicas, 62(93), 193-204.

Nora, P. (2009). Pierre Nora en Les Lieux de mémoire. Santiago: Editorial Lom.

Piper, I. \& Hevia, E. (2012). Espacio y recuerdo: archipiélago de memorias en Santiago de Chile ( $1^{\mathrm{a}}$ ed.). Santiago, Chile: Ocho Libros Editores.

Piper, I.; Fernández, R. \& Iñiguez, L. (2013). Psicología Social de la Memoria: Espacios y Políticas del Recuerdo. Revista Psykhe, 22(2), 19-31. http://dx.doi.org/10.7764/ psykhe.22.2.574.

Reyes, M. J., Cruz, M. A., \& Aguirre, F. J. (2016). Los lugares de memoria y las nuevas generaciones: algunos efectos políticos de la transmisión de memorias del pasado reciente de Chile. Revista Española de Ciencia Política, 41, 93-114. http://doi.org/10.21308/recp.41.04

Rozas, V. (2013). Tres maneras de explicar la presencia de graderías antiguas en un Estadio remodelado, Bifurcaciones, 14. http://www.bifurcaciones.cl/2013/10/graderias-antiguasen-un-estadio-remodelado/

Sánchez De La Yncera, I. (1993). Presentación. La sociología ante el problema generacional. Anotaciones al trabajo de Karl Mannheim. Reis: Revista Española de Investigaciones Sociológicas, 62(93), 147-192.

Richard, N. (2010). Crítica de la memoria (1990-2010). Santiago: Ediciones Universidad Diego Portales.

Ruderer, S. (2010). La política del pasado en Chile 1990-2006: ¿un modelo chileno? Universum, 25(2), 161-177.

Ruiz, J. (2012). El grupo triangular: reflexiones metodológicas en torno a dos experiencias de investigación, Empiria: Revista de metodología de ciencias sociales, 24, 141-162, https://doi.org/10.5944/empiria.24.2012.846

Sarlo, B. (2005). Tiempo pasado: cultura de la memoria y giro subjetivo: una discusión. Buenos Aires: Siglo XXI.

Schindel, E. \& Colombo, P. (Eds.). (2015). Space and the Memories of Violence. Landscapes of Erasure, Disappearance and Exception. London: Palgrave Macmillan.

Stern, S. \& Winn, P. (2014). El tortuoso camino chileno a la memorialización. In P. Winn (Ed.), No hay mañana sin ayer. Batallas por la memoria histórica en el Cono Sur (pp. 205326). Santiago de Chile: LOM.

Todorov, T. (2000). Los abusos de la memoria. España: Ediciones Paidós Ibérica.

Winn, P. (Ed.). (2014). No hay mañana sin ayer: batallas por la memoria histórica en el Cono Sur. Santiago: Lom Ediciones.

\section{Contexto da pesquisa e Agências de fomento}

Este artículo da cuenta de los resultados obtenidos en el proyecto Fondecyt Regular N ${ }^{\circ} 1110162$ "Construcción de relatos generacionales sobre nuestro pasado reciente (1970-1990) en el escenario de cuatro lugares de memoria de Santiago" y el proyecto Fondo de Innovación en Investigación IBJGM. Proyecto Bicentenario 2013. Perfil 1 "Memorias generaciones, experiencia, género y materialidades: análisis semiótico material de discursos de no - víctimas de las violaciones a los Derechos Humanos". Esta investigación se desarrolló en el marco del Programa Psicología Social de la Memoria de la Universidad de Chile y del Grupo de Trabajo CLACSO "Memorias Colectivas y Prácticas de Resistencias".

Submissão em: 15/05/2017

Revisão em: 29/01/2018

Aceite em: 08/04/2018

Roberto Fernández Droguett es Académico e investigador del Programa Psicología Social de la Memoria, Departamento de Psicología, Universidad de Chile. Doctor en Arquitectura y Estudios Urbanos, Pontificia Universidad

Católica de Chile. https://orcid.org/0000-0001-9956-0312

Dirección: Departamento de Psicología/Facultad de Ciencias Sociales de la Universidad de Chile. Av.Capitán Ignacio Carrera Pinto Nº1045, Nuñoa, Santiago de Chile. E-mail: rfd2003@gmail.com

Loreto López González es Investigadora del Programa Psicología Social de la Memoria, Universidad de Chile. Doctora en Ciencias Sociales, Universidad de Chile. Investigadora Grupo de Trabajo CLACSO Memorias Colectivas y Prácticas de Resistencia. http://orcid.org/0000-0001-9982-7689 E-mail: 1oreto.lg@gmail.com

Isabel Piper Shafir es Académica del Departamento de Psicología de la Universidad de Chile. Coordinadora del Programa Psicología Social de la Memoria de la misma Universidad, y del Grupo de Trabajo CLACSO Memorias Colectivas y Prácticas de Resistencia. Doctora en Psicología Social, Universitat Autonoma de Barcelona. http://orcid.org/0000-0001-6795-2573 E-mail: ipiper@uchile.cl 